\title{
A Research on the Economic Feasibility of Korean Nucle- ar Power under the Condition of Social Acceptance after Fukushima Accident
}

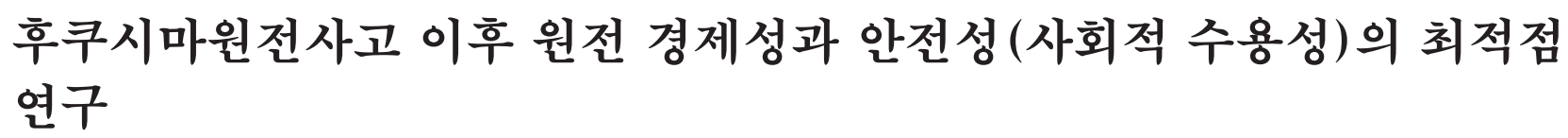

Dong-Won Kim

Korea Nuclear Energy Promotion Agency, 1418 Nambusunhwanno, Geumcheon-gu, Seoul, Korea

김동원

한국원자력문화재단, 서울특별시 금천구 남부순환로 1418

(Received June 7, 2013 / Revised June 25, 2013 / Approved September 5, 2013)

Since the Fukushima nuclear power plant accident in March 2011, critical views on the increase in operation of nuclear power plants including the safety and the economic feasibility thereof have been expanding across the world. In these circumstances, we are to find out solutions to the controversial questions on whether nuclear power plants are economically more feasible than other energy sources, while the safety thereof is fully maintained. Thereby, nuclear power plants will play a key role as a sustainable energy source in the future as well as at present. To measure the social safety level that Korean people are actually feeling after the Fukushima accident, a method of cost-benefit analysis called the Contingent Valuation Method(CVM) was used, whereby we wanted to estimate the amount of expenses the general public would be willing to pay for the safety based on their acceptance rather than the social safety. As a result of calculating the trade-off value of the economic feasibility versus the safety in nuclear power plants through the survey thereon, it caused the nuclear power generation cost to be increased by 4.75 won $/ \mathrm{kWh}$. Reflecting this on the current power generation cost of $39.11 \mathrm{won} / \mathrm{kWh}$ would increase the cost to 43.86 won/kWh. It is thought that this potential cost is still more competitive than the coal-fired power generation cost of 67 won/kWh. This result will be available as a basic data for the 2nd Energy Basic Plan to be drawn up this year, presenting policy implications at the same time.

Key words: Contingent Valuation Method, Optimum Point, Economic Feasibility, Social Acceptance, Nuclear power generation cost

2011년 3월 발생한 일본의 후쿠시마 원전 사고는 원전의 안전성 문제를 넘어 경제성까지 논란을 불러일으키고 있으며, 이 러한 문제는 원전 확대에 대한 비판적 시각을 전 세계적으로 확대시키고 있다. 따라서 원전이 안전성을 충분히 유지하면서 도 타 전원에 비해 경제성이 있다는 것을 입증한다면 현재는 물론 지속가능한 전원으로서의 원전의 역할을 기대할 수 있을 것이다.

후쿠시마 원전사고 이후 국민들이 실제로 느끼는 ‘사회적 안전성’ 정도를 알아보기 위해 안전성 대신 일반국민의 수용성을 지표로 삼아 안전에 대한 비용을 얼마나 지불할 수 있느냐를 알아보기 위해 비용편익분석의 하나인 조건부가치측정법(CVM: contingent valuation method)을 이용하였다. 경제성과 안전성의 trade-off값을 설문조사를 통해 알아본 결과 발전원가 4.75 원/kWh 인상효과를 가져왔다. 이를 현재 원전발전단가 39.11 원 $/ \mathrm{kWh}$ 에 반영하면 43.86 원 $/ \mathrm{kWh}$ 으로 석탄화력 발전원가 
Dong-Won Kim : A Research on the Economic Feasibility of Korean Nuclear Power under the Condition of Social Acceptance after Fukushima Accident

67 원 $/ \mathrm{kWh}$ 과 비교해 여전히 경쟁력이 있는 것으로 나타났다. 이러한 결과는 2013년 말 수립예정인 제 2 차 에너지기본계획[1] 등에 기초자료로 중요한 정책적 시사점을 가져다 줄 것이다.

중심단어 : 조건부가치측정법, 최적점, 경제성, 사회적 수용성, 원전발전단가

*Corresponding Author. E-mail: dwkim@konepa.or.kr, Tel: +82.02.2191.1310

\section{1. 서 론}

2011년 3월 발생한 일본의 후쿠시마 원전 사고 이후의 변화된 상황 속에서 원전이 안전성을 충분히 유지하면서 도 타 전원에 비해 경제성이 있다는 것을 보여줄 수 있다 면 현재는 물론 지속가능한 전원으로서 원전의 역할을 기 대해 볼 수 있을 것이다.

이러한 관점에서 후쿠시마 원전사고 이후 '기술적 안전 성'이 아닌 국민들이 실제로 느끼는 '사회적 안전성' 정도를 일반국민의 수용성 지표로 대신하여, 안전에 대한 비용을 얼마나 지불할 수 있느냐를 알아보기 위해 비용편익분석 의 하나인 이른바 조건부가치측정법[2](CVM: contingent valuation method)을 이용하여 안전에 대한 지불용의 비 용을 설문조사를 통해 알아봄으로서, 안전성과 경제성의 trade-off 점을 찾아보았다. 이 결과는 2013년 말 수립예정 인 제 2 차 에너지기본계획 등 에너지 믹스의 기초자료로서 중요한 정책적 시사점을 가져다 줄 것이다.

\section{2. 조사개요}

과거 조건부가치측정법을 이용하여 영월 동강댐의 환

Table 1. Summary of Cost-Benefit Analysis of Nuclear Power Plants

\begin{tabular}{ll}
\hline \multicolumn{1}{c}{ Cost } & \multicolumn{1}{c}{ Benefit } \\
\hline - Cost for power generation & \\
- Post-Management Cost for & - Securing stable electric power \\
Nuclear Power Plants & - Energy security \\
- Subsidies for the areas near the & - Cheap electric power \\
nuclear power plants & - Climate change \\
- R\&D expenses & \\
- Cost on Compensation and & \\
Liability for Nuclear Damage & \\
\end{tabular}

경비용[3], 청계천복원사업에 따른 환경편익[4], 소비자들 의 도시가스안정성 제고를 위한 지불의사금액[5]을 추정한 것을 참고하면 원전의 경우 편익측면에서는 안정적 전력 확보, 에너지안보, 값싼 전력, 기후변화 등을 들 수 있고, 비용측면에서는 기존발전비용에 더하여 원전사후처리비 용, 발전소주변지역지원금, $\mathrm{R} \& \mathrm{D}$, 보험금 등을 들 수 있다. 그 결과는 Table 1 과 같다.

후쿠시마 사고 이후 국민의 원전에 대한 사회적 안전 성(수용성:사회적 안전성의 지표) 우려가 심하여 수용성을 국민들의 눈높이로 맞추기 위해 필요한 비용의 지불의사 를 조건부가치측정법을 이용하여 평가하였다.

2011년 발전단가인 원전 39 원 $/ \mathrm{kWh}$, 석탄 67 원 $/ \mathrm{kWh}$ 을 기준으로 설문한 결과를 분석해 보았다. 설문내용은 Table 2와 같다.

\section{1 조사설계}

본 조사를 수행하기 위한 조사설계는 Table 3과 같다. 본 조사는 전국 만 20세 이상 성인남녀를 대상으로 조 사를 진행하였으며, 2010년 통계청 인구총조사 결과에 따 른 성별, 연령별, 지역별 비례할당 후 무작위추출방식으로

Table 2. Contents of the Survey

\begin{tabular}{ll}
\hline 1. Necessity of nuclear power \\
2. Safety of nuclear power \\
3. Intent to pay additional electric charges \\
Awareness on & $\begin{array}{l}\text { 4. Reasons for not being able to pay additional } \\
\text { nuclear power }\end{array}$ \\
& $\begin{array}{l}\text { 5. Intent to pay additional 5,000 won or above for } \\
\text { electric charges } \\
\text { 6. The ceiling amount for additional charges }\end{array}$
\end{tabular}


진행하였다. 실제조사는 전문기관이 보유한 전국 온라인 패널을 대상으로 진행하였고, 유효표본은 1,030 명, 표본오 차는 $95 \%$ 신뢰수준에서 $\pm 2.8 \%$ 이다.

\section{2 표본구성}

본 연구는 전국 국민의 원자력에너지에 대한 인식과 태도, 그리고 안전성 제고비용을 추정하기 위한 목적으로 수행하였으므로, 조사대상은 전국 인구비율에 따라 할당 되도록 표본을 설계하였다. 조사 응답자의 일반적 특성은 Table 4와 같다.

총 1,030명으로부터 유효한 응답을 확보하였으며, 성별로는 남성 $51.4 \%$, 여성 $48.6 \%$ 였다. 연령대는 20 대 $22.1 \%, 30$ 대 $24.2 \%, 40$ 대 $23.9 \%, 50$ 대 $15.0 \%, 60$ 세 이상 $14.8 \%$ 로 파악되었다.

학력으로는 고졸 이하 $72.7 \%$, 초대졸 $12.6 \%$, 대학원 이상 $14.7 \%$ 로 파악되었다.

거주지별로는 서울 $22.5 \%$, 경기·인천 $27.8 \%$, 충청권 $10.1 \%$, 경상권 $27.2 \%$, 전라권 $8.2 \%$, 강원 - 제주 $4.3 \%$ 로 파악되었다.

직업별로는 사무직 $29.6 \%$, 행정·전문·기술전문직 $21.1 \%$, 상업 - 서비스직 $13.6 \%$, 노무·기능직 $4.1 \%$, 주부 $16.7 \%$, 대학생 · 무직 · 기타 $15.0 \%$ 로 구성되었다.

\section{3 자료처리방법}

본 연구에서 수집한 자료는 SPSS 20.0(컴퓨터를 이용

Table 3. Survey Design

\begin{tabular}{cl}
\hline Category & \multicolumn{1}{c}{ National Survey } \\
\hline Population & Male and female adults of 20 years old or above \\
\hline $\begin{array}{c}\text { Size of } \\
\text { specimen }\end{array}$ & Effective specimen of 1,030 people \\
\hline Sampling & $\begin{array}{l}\text { Random sampling after proportionate allocation } \\
\text { of sex, age and place of residence in accordance } \\
\text { with the results of the 2010 census by the National } \\
\text { Statistical Office }\end{array}$ \\
\hline Sampling error & $\begin{array}{l}\text { Based on random sampling, confidence level of } \\
95 \% \pm 2.8 \%\end{array}$ \\
\hline Survey method & Online survey using national online panels \\
\hline Survey period & April 29, 2013 to May 25, 2013 \\
\hline
\end{tabular}

하여 복잡한 자료를 쉽게 처리할 수 있도록 만든 통계분석 프로그램)을 이용하여 분석하였으며, 분석방법은 빈도분 석, 교차분석, 그리고 평균차이분석인 t-test 및 분산분석을

Table 4. General Characteristics of Survey Results

\begin{tabular}{|c|c|c|c|}
\hline Variables & Category & $\begin{array}{l}\text { Frequency } \\
\text { (Number of } \\
\text { people) }\end{array}$ & $\begin{array}{c}\text { Ratio } \\
(\%)\end{array}$ \\
\hline \multirow{2}{*}{ Sex } & Male & 529 & 51.4 \\
\hline & Female & 501 & 48.6 \\
\hline \multirow{5}{*}{ Age } & $20-29$ years of age & 228 & 22.1 \\
\hline & $30-39$ years of age & 249 & 24.2 \\
\hline & $40-49$ years of age & 246 & 23.9 \\
\hline & $50-59$ years of age & 155 & 15.0 \\
\hline & 60 and above & 152 & 14.8 \\
\hline \multirow{3}{*}{$\begin{array}{c}\text { Acade } \\
\text { mic } \\
\text { Background }\end{array}$} & $\begin{array}{l}\text { High school graduates } \\
\text { and below }\end{array}$ & 749 & 72.7 \\
\hline & Junior college graduates & 130 & 12.6 \\
\hline & $\begin{array}{l}\text { Graduate school } \\
\text { graduates }\end{array}$ & 151 & 14.7 \\
\hline \multirow{6}{*}{$\begin{array}{l}\text { Place of } \\
\text { Residence }\end{array}$} & Seoul & 232 & 22.5 \\
\hline & Gyeonggi / Incheon & 286 & 27.8 \\
\hline & Chungcheong & 104 & 10.1 \\
\hline & Gyeongsang & 280 & 27.2 \\
\hline & Jeonra & 84 & 8.2 \\
\hline & Gangwon /Jeju & 44 & 4.3 \\
\hline \multirow{7}{*}{ Occupation } & Office work & 305 & 29.6 \\
\hline & $\begin{array}{l}\text { Administrative / } \\
\text { Professional } \\
\text { /Technical professional } \\
\text { work }\end{array}$ & 217 & 21.1 \\
\hline & Sales/ Services & 140 & 13.6 \\
\hline & Labor / Functional & 42 & 4.1 \\
\hline & Housewives & 172 & 16.7 \\
\hline & $\begin{array}{l}\text { University students/ } \\
\text { Unemployed/ Other }\end{array}$ & 154 & 15.0 \\
\hline & Total & 1030 & 100.0 \\
\hline
\end{tabular}


Dong-Won Kim : A Research on the Economic Feasibility of Korean Nuclear Power under the Condition of Social Acceptance after Fukushima Accident

Table 5. Reasons why nuclear power plants are necessary

\begin{tabular}{cccccc}
\hline \multirow{2}{*}{ Category } & $\begin{array}{c}\text { Mass supply of } \\
\text { electricity }\end{array}$ & $\begin{array}{c}\text { Cheap use of } \\
\text { electricity }\end{array}$ & $\begin{array}{c}\text { For energy security of } \\
\text { Korea }\end{array}$ & $\begin{array}{c}\text { Energy suitable for } \\
\text { global climate change }\end{array}$ & Total \\
\hline \multirow{2}{*}{ Total } & 368 & 316 & 206 & 140 & 1,030 \\
\cline { 2 - 8 } & 35.7 & 30.7 & 20.0 & 13.6 & 100.0 \\
\hline
\end{tabular}

Table 6. Opinions on the safety of nuclear power plants

\begin{tabular}{ccccccc}
\hline \multicolumn{2}{c}{ Category } & Very safe & Relatively safe & Not very safe & Not safe at all & Total \\
\hline \multirow{2}{*}{ Total } & Number & 32 & 473 & 401 & 124 & 1,030 \\
\cline { 2 - 8 } & 3.1 & 45.9 & 38.9 & 12.0 & 100 \\
\hline
\end{tabular}

Table 7. Intent to pay additional electric charges for the safety of nuclear power plants

\begin{tabular}{|c|c|c|c|c|}
\hline & Category & $\begin{array}{c}\text { Willing to pay } \\
\text { additional } \\
\text { charges }\end{array}$ & $\begin{array}{c}\text { Not willing to } \\
\text { pay additional } \\
\text { charges }\end{array}$ & Total \\
\hline \multirow{2}{*}{$\begin{array}{l}\text { To } \\
\text { tal }\end{array}$} & Number & 273 & 252 & 525 \\
\hline & $\%$ & 52.0 & 48.0 & 100.0 \\
\hline
\end{tabular}

적용하였다. 또한 $\mathrm{CVM}$ 기법을 적용하여 원전에 대한 안전 성제고비용을 추정하였다. 본 연구의 유의수준은 $\alpha=0.05$ 로 설정하였다.

\section{3. 조사결과}

\section{1 원자력발전소가 필요한 이유}

먼저 '우리나라에서는 원자력발전소가 여러 가지 측면 에서 필요한 에너지입니다. 귀하께서는 다음 중 어떤 측 면에서 원자력발전소가 필요하다고 생각하십니까?'라는 원자력발전소 필요 이유에 대해서 응답한 결과는 Table 5와 같다. '전기를 대량으로 공급할 수 있다'가 $35.7 \%$ 로 가장 높게 나타났으며, 다음 '전기를 저렴하게 쓸 수 있 다'가 $30.7 \%$, '우리나라의 에너지안보 측면에서 필요하 다'(20.0\%), '지구기후변화에 적합한 에너지다'(13.6\%) 순 으로 응답이 나타났다.

\section{2 원자력발전소 안전성에 대한 의견}

다음으로 '귀하께서는 원자력발전소가 안전하다고 생 각하십니까? 안전하지 않다고 생각하십니까?라는 질문 에 대해서 Table 6과 같은 응답이 나타났다. 안전하다가 $49.0 \%$ (매우 안전하다 $3.1 \%$, 안전한 편이다 $45.9 \%$ )인 반 면, 안전하지 않다는 $51.0 \%$ (안전하지 않은 편이다 $38.9 \%$, 전혀 안전하지 않다 $12.0 \%)$ 로 각각 나타났다.

\section{3 원자력발전소 안전성 제고를 위한 추가부담 의향}

다음으로 '귀하께서는 원자력발전소가 안전하지 않다 고 생각하십니다. 원자력발전소가 안심할 정도로 안전하 려면 지금보다 건설비를 더 들여야 합니다. 이로 인한 부 담을 소비자가 더 부담해야 한다면, 이를 위해 전기료를 조 금이라도 더 내실 의향이 있으십니까?'에 대한 응답 결과 는 Table 7과 같다. 원자력 발전소에 안전하지 않다고 생 각하는 525 명 중 안전성 제고를 위해 추가부담을 낼 의향 이 있는 비율은 $52.0 \%$ 인 반면 추가지불 의향이 없는 비율 은 $48.0 \%$ 로 나타났다.

\section{4 추가전기료 부담 의향이 없는 이유}

다음으로 원자력발전소가 안전하지 않으나 안전성 제 고를 위해서 추가 지불 의향이 없는 사람을 대상으로 '귀 하께서는 전기료를 더 내실 의향이 없다고 하셨습니다. 다 음 중 어떤 이유로 그렇게 생각하십니까?'라는 질문에 대 
Dong-Won Kim : A Research on the Economic Feasibility of Korean Nuclear Power under the Condition of Social Acceptance after Fukushima Accident

Table 8. Reasons for not being able to pay additional electric charges

\begin{tabular}{cccccc}
\hline Category & $\begin{array}{c}\text { There are power plants } \\
\text { other than nuclear power } \\
\text { plants }\end{array}$ & $\begin{array}{c}\text { This should be covered } \\
\text { by the government } \\
\text { or KEPCO }\end{array}$ & $\begin{array}{c}\text { Not able to decide due to } \\
\text { lack of knowledged on } \\
\text { safety of nuclear power } \\
\text { plants }\end{array}$ & $\begin{array}{c}\text { Not able to } \\
\text { afford }\end{array}$ & Other \\
\hline Total & 35 & 78 & 50 & 59 & 30 \\
\cline { 2 - 8 } & 13.9 & 31.0 & 19.8 & 23 & 11.9 \\
\hline
\end{tabular}

Table 9. Intent to pay additional 5,000 won or higher monthly for electric charges

\begin{tabular}{ccccc}
\hline \multicolumn{2}{c}{ Category } & Willing & Not willing & Total \\
\hline \multirow{2}{*}{ Total } & Number & 190 & 83 & 273 \\
\cline { 2 - 5 } & $\%$ & $69.6 \%$ & $30.4 \%$ & $100.0 \%$ \\
\hline
\end{tabular}

Table 10. Additional amount to be paid monthly

\begin{tabular}{cccc}
\hline Category & Frequency & Average & $\begin{array}{c}\text { Standard } \\
\text { Deviation* }\end{array}$ \\
\hline Total & 273 & $\begin{array}{c}7468.1 \\
\text { won }\end{array}$ & $\begin{array}{c}8618.7 \\
\text { won }\end{array}$ \\
\hline
\end{tabular}

*Standard Deviation shows how much the variation or dispersion from the average exists. The number 8618.7 won indicates that the data tends to be spread out over a large range.

한 응답 결과는 Table 8과 같다. '정부나 한전에서 해야 할 일이므로'가 $31.0 \%$ 으로 가장 높고, 다음 '경제적 여건이 어 렵기 때문에' $23.4 \%$, '원자력발전소 안전에 대한 정보/지식 이 부족하여 결정할 수가 없어서' $19.8 \%$, '원자력발전소가 아니더라도 다른 화력발전소가 있기 때문에' $13.9 \%$, 기타 $11.9 \%$ 순으로 나타났다.

\section{5 전기료 매월 5,000 원 이상 추가 지불 의향}

다음으로 전기료 추가 지불의향이 있다는 273 명을 대 상으로 5,000원 이상 지불의향에 대해 추가적으로 '귀하께 서는 전기료를 조금이라도 더 내실 의향이 있다고 하셨는 데 그렇다면 매월 5,000원을 더 내실 용의가 있으십니까?' 라고 질문한 응답 결과는 Table 9와 같다. 전체 응답을 보 면 있다가 $69.6 \%$, 없다가 $30.4 \%$ 로서 5,000원 이상 추가지 불 의향이 있다는 응답자가 더 높게 나타났다.

\section{6 매월 추가지불 금액}

그렇다면 귀하께서는 매월 추가로 지불할 용의가 있 는 최대금액은 얼마입니까?'라는 질문에 대한 응답결과는 Table 10 과 같다. 전체 응답결과, 추가지불금액의 평균은 7,468원으로 나타났으며 표준편차는 8,618원으로 파악되 었다.

설문결과에서 나타난 자료를 기초로 대한민국 국민 의 원전에 관한 불안한 마음을 안심하게 하는 데 필요한 비용을 경제적 가치로 환산하면, 안전하지 않다라고 생각 하는 국민이 $50.9 \%$ (안전하지 않은 편이다+전혀 안전하 지 않다), 이 중에서 원전 안전을 위한 지불용의가 있다 가 $52.0 \%$, 또한 지불용의가 없는 $48.0 \%$ 중에서도 화력발 전소로 대체할 수 있다라고 대답(13.9\%)한 응답자를 제 외한 $41.3 \%[48.0 \% \times(100-13.9 \%)]$ 는 응답자가 아닌 다른 주체가 지불해야 한다라고 생각하는 것이므로, 지불용의 응답자의 가구당 월평균 지불용의는 7,468 원, 가구수는 20,223,716가구(2013년 1월 현재)이므로 우리나라 국민의 연간 지불용의총액을 계산하면 다음과 같다.

7,468 원 $\times 20,223,716$ 가구 $\times 0.509 \times(0.520+0.413) \times 12$ 월 $=860,688,379,248$ 원

대한민국 원전 23기를 연간 운영하여 얻는 발전량은 $1,000,000 \mathrm{~kW}(23$ 기평균용량 $) \times 8,760 \mathrm{hr} \times 23$ 기 $\times 0.9$ (평균이 용률 $90 \%$ 가정 $=181,332,000,000 \mathrm{kwh}$ 이므로 860,688,379,248원 $\div 181,332,000,000 \mathrm{kwh}=4.75$ 원/kWh

즉 원전의 안전 확보를 위하여 국민 수용성 측면에서 발전원가 4.75 원 추가적인 비용의 인상효과를 가져온다. 이를 현재 39.11 원/kWh에 반영하면 43.86 원/kWh이 되 는데, 석탄화력발전원가 67 원 $/ \mathrm{kWh}$ 에 비해서는 여전히 경쟁력이 있다고 판단된다. 
Dong-Won Kim : A Research on the Economic Feasibility of Korean Nuclear Power under the Condition of Social Acceptance after Fukushima Accident

\section{4. 결 론}

이 논문의 한계점은 설문지를 통해 지불의사금액을 확 보하는 방법으로 가장 많이 쓰는 양분선택법(응답자로 하 여금 주어진 지불의사액에 대해 예/아니오만 답하면 되는 방식)을 썼지만 단 1 회만을 제시하였고 또한 제시금액도 필자의 의도로 5,000원이라는 조금 높은 가격(2011년 가 구당 평균 전기요금 월 29,122원)을 제시함으로써 많은 지 불용의금액을 유도하였다. 이는 국민들의 지불용의 금액 을 최대한 높였음에도 경제성이 유지됨을 자신할 수 있는 의도로 제시하였다.

이러한 결론은 몇 가지 불확실성은 있지만 국민들의 원 전안전에 대한 지불용의 금액(WTP)이라는 점에서 정책판 단의 자료로 활용할 수 있다 하겠다.

"원전을 당장 화력발전으로 대체할 경우 15 조원의 추 가비용이 발생하여 가구 당 연간 약 860,000원(월 71,670 원)을 추가로 부담해야 함"(지식경제부, 2012)과 견주어 봐도 국민들이 원전안전을 포기하고 화력발전으로 대체 하는 수용용의보다 원전안전을 위한 지불용의가 훨씬 저 렴하므로 사회적 수용성을 위한 지불이 충분히 경제적으 로 우위에 있다고 하겠다.

\section{REFERENCES}

[1] Press Release of the Ministry of Trade, Industry and Energy, "The Government, NGOs, Academics and Industries are Gathered for the Decision of Energy Mix in 2035" (2013).

[2] S.W. Kim, H.G. Kim, S.H. Yoo, H.S. Lee, J.S. Lim, T.Y. Jeong, T.W. Han and J.H. Hong, "The Theory and the Reality of Environmental Economics", pp. 119-151(2008).

[3] S.J. Kwak and S.H. Yoo, "Social Costs of Environmenal Damage due to Youngwol Dam: Estimation of Currency Value of Environmental Preservation", Korea University Economics Research Center (1999).

[4] Y.S. Lee, Costs, "Benefits and the Economic Effects of the Restoration of Chunggyecheon", Seoul Economics of The Seoul Institute, pp. 46-53 (2005).

[5] Y.S. Cho, "Analysis of the Social Costs and Benefits of the City Gas Safety Management System: Based on the Estimation of the Willingness to Pay for the Safety of City Gas", Research Paper 99-09, Korea Energy Economics Institute (1999). 